\title{
Thiosemicarbazones Synthesized from Acetophenones: Tautomerism, Spectrometric Data, Reactivity and Theoretical Calculations
}

\author{
Belén Gastaca', Hernán Rubén Sánchez ${ }^{2}$, Fiorella Menestrina ${ }^{3}$, Maricel Caputo ${ }^{1}$, \\ María de las Mercedes Schiavoni1 ${ }^{1}$ Jorge Javier Pedro Furlong1 ${ }^{*}$ \\ ${ }^{1}$ Laboratory of Organic Compounds Studies (LADECOR), Department of Chemistry, Facultad de Ciencias Exactas, National \\ University of La Plata, La Plata, Argentina \\ ${ }^{2}$ Institute of Physics of Liquids and Biological Systems (IFLySIB, CONICET), National University of La Plata, La Plata, Argentina \\ ${ }^{3}$ Laboratory of Research and Development of Analytical Methods (LIDMA), Department of Chemistry, \\ Facultad de Ciencias Exactas, National University of La Plata, La Plata, Argentina \\ Email: belgastaca@gmail.com, hernan.sanchez.ds@gmail.com, menestrinafiorella@gmail.com, maric323@hotmail.com, \\ mms@quimica.unlp.edu.ar, ^furlong@quimica.unlp.edu.ar
}

How to cite this paper: Gastaca, B., Sánchez, H.R., Menestrina, F., Caputo, M., de las Mercedes Schiavoni, M. and Furlong, J.J.P. (2019) Thiosemicarbazones Synthesized from Acetophenones: Tautomerism, Spectrometric Data, Reactivity and Theoretical Calculations. International Journal of Analytical Mass Spectrometry and Chromatography, 7, 19-34.

https://doi.org/10.4236/ijamsc.2019.72003

Received: May 5, 2019

Accepted: June 25, 2019

Published: June 28, 2019

Copyright $\odot 2019$ by author(s) and Scientific Research Publishing Inc. This work is licensed under the Creative Commons Attribution International License (CC BY 4.0). http://creativecommons.org/licenses/by/4.0/

\begin{abstract}
Tautomeric forms of Thiosemicarbazones have been investigated by spectrometric methods, their chemical reactivity and theoretical calculations of the relative tautomers stabilities. The mass spectral fragmentation of thiosemicarbazones synthesized from acetophenones has been studied by CG/MS. The analysis of the corresponding spectra shows not only the regular fragmentation mechanisms but homolytic ruptures from even-electron species. ${ }^{1} \mathrm{H}$ NMR spectra exhibit signals for the most intense open thioketo tautomeric structure, although when using TFA a ring structure is observed in the corresponding tautomeric equilibrium. Density Functional Theory calculations (DFT) also provide evidence to support the experimental observations by GC-MS and ${ }^{1} \mathrm{H}$ NMR. Methylation reactions give support to the occurrence of the thioenol tautomeric form which would be the second most abundant according to the Density Functional Theoretical calculations.
\end{abstract}

\section{Keywords}

Thiosemicarbazones, Tautomerism, MS, NMR, Theoretical Calculations

\section{Introduction}

Among semicarbazones, thiosemicarbazones have particular interest due to their bioactivity as well as their structural properties. 
These substances exhibit a wide variety of biological activities as, for example, antitumor, antibacterial, antiviral, antiprotozoal activity and cytotoxic effects [1].

Chagas-Mazza disease is a widely spread disease in rural areas of South and Central America and it was reported that these compounds may constitute an alternative treatment. Thiosemicarbazones can inhibit cruzain, which is the major cysteine protease present in Trypanosome cruzi that is expressed in every step of the life of the parasite that causes the mentioned disease [2].

These molecules exhibit tautomeric equilibria what is certainly relevant because the occurrence of a particular tautomer determines the reactivity. Thiosemicarbazones can exhibit several tautomers [3] with open and ring structures. Open keto-forms are certainly the most stable ones. Scheme 1 shows all the possible tautomeric forms for the thiosemicarbazone of acetophenone.

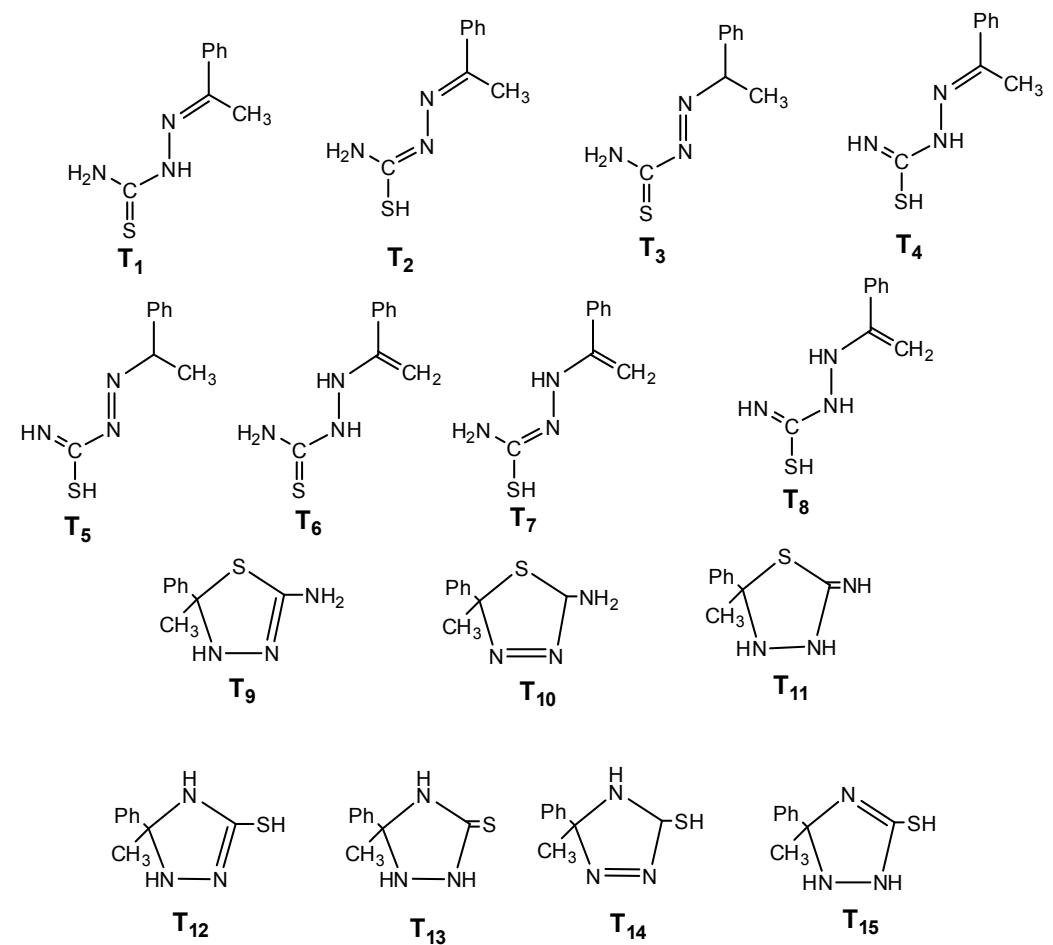

\begin{tabular}{ccc}
\hline Open Chain Forms & Thioketo & Thioenol \\
\hline $\begin{array}{c}\text { Conjugated Phenyl } \\
\text { Non conjugated Phenyl }\end{array}$ & $\mathrm{T}_{1}, \mathrm{~T}_{6}$ & $\mathrm{~T}_{2}, \mathrm{~T}_{4}, \mathrm{~T}_{7}, \mathrm{~T}_{8}$ \\
\hline Ring Forms & $\mathrm{T}_{3}$ & $\mathrm{~T}_{5}$ \\
\hline $\begin{array}{c}\text { Exocyclic- } \mathrm{NH}_{2} \\
\text { or Exocyclic-SH }\end{array}$ & $S$-ring & N-ring \\
$\begin{array}{c}\text { Exocyclic }=\mathrm{NH} \\
\text { or Exocyclic }=\mathrm{S}\end{array}$ & $\mathrm{T}_{9}, \mathrm{~T}_{10}$ & $\mathrm{~T}_{12}, \mathrm{~T}_{14}, \mathrm{~T}_{15}$ \\
\hline
\end{tabular}

Scheme 1. Tautomeric forms for thiosemicarbazones of acetophenone. 
Ring structures have been investigated by NMR [4] and it has been shown that the solvent polarity modifies the equilibria. The 4-methyl and the 2-methyl-thiosemicarbazones of acetone convert readily into the corresponding 1,2,4-triazolidine-3-thiones in deuterated trifluoroacetic acid, while they are present exclusively as the open-chain forms in $\mathrm{d}_{6}$-dimethylsulfoxide.

Semicarbazones and thiosemicarbazones can form complexes with metals and several of them have exhibit biological activity (particularly antimicrobial and antitumor activity have been reported) [5] [6] [7]. Additionally, they have been used as corrosion inhibitors of certain alloys [8].

In this work, a study of thiosemicarbazones synthetized from substituted acetophenones is carried out by means of gas chromatography-mass spectrometry, ${ }^{1} \mathrm{H}-\mathrm{NMR}$ and theoretical calculations. It has been reported that the GCMS spectra revealed not only the dissociation of the thiosemicarbazones in the injection port but also the formation of compounds of higher molecular weight with longer retention times [9]. Additionally, unusual fragmentation routes (homolytic ruptures of even-electron ions) are observed. Density Functional Theory (DFT) [10] [11] [12] [13] calculations were carried out to investigate stability among tautomeric forms in order to have answers on the reactivity and spectral behavior. It is well known that computational tools are of great aid to gain insights that could help to understand and predict the structure, stability, and reactivity of organic compounds. Among them, methods based on the DFT have proven to be very effective.

\section{Materials and Methodology}

The compounds under study were synthesized by adapting literature procedures [14] [15]. Table 1 depicts the corresponding mass spectral data for thiosemicarbazone of acetophenone (I), MW $193 \mathrm{amu}$, thiosemicarbazone of 4-chloroacetophenone (II), MW $227 \mathrm{amu}$, thiosemicarbazone of 4-nitroacetophenone (III), MW $238 \mathrm{amu}$, thiosemicarbazone of 4-methylacetophenone (IV), MW $207 \mathrm{amu}$ and thiosemicarbazone of 4-oxymethyl acetophenone (V), MW $223 \mathrm{amu}$.

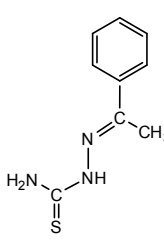

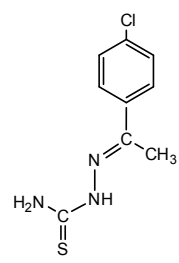

II

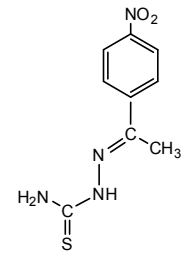

III
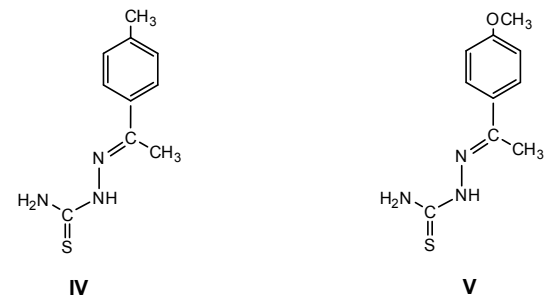
Table 1. Relevant spectrometric data of thiosemicarbazones $(\mathrm{I}-\mathrm{V})^{\star}$.

\begin{tabular}{cccccc}
\hline & I & II & III & IV & V \\
\hline $\mathrm{M}^{+}$ & $193(0.0)$ & $227(0.0) / 229(0.0)$ & $238(0.0)$ & $207(0.0)$ & $223(0.0)$ \\
$\left(\mathrm{M}-\mathrm{NH}_{2}\right)^{+}$ & $177(3.0)$ & $211(4.9) / 213(1.8)$ & $222(5.4)$ & $191(10.5)$ & $207(10.0)$ \\
$\left(\mathrm{M}-N H_{3}\right)^{+}$ & $176(32.1)$ & $210(39.1) / 212(15.3)$ & $221(43.3)$ & $190(47.0)$ & $206(67.3)$ \\
$\left(\mathrm{M}-\mathrm{CH}_{3}\right)^{+}$ & $178(1.5)$ & $212(15.3) / 214(<1)$ & $223(<1)$ & $192(<1)$ & $208(2.6)$ \\
$(\mathrm{M}-\mathrm{SCNH})^{+}$ & $134(2.2)$ & $168(10.8) / 170(4.1)$ & $179(7.7)$ & $148(5.5)$ & $164(2.6)$ \\
$\left(\mathrm{M}-\mathrm{SCN}_{2} \mathrm{H}_{2}\right)^{+}$ & $119(6.2)$ & $153(17.0) / 155(5.8)$ & $164(18.0)$ & $133(32.0)$ & $149(15.9)$ \\
$\left(\mathrm{M}-\mathrm{SCN}_{2} \mathrm{H}_{3}\right)^{+}$ & $118(39.8)$ & $152(69.1) / 154(21.6)$ & $163(50.3)$ & $132(43.5)$ & $148(100.0)$ \\
$\left(\mathrm{ArCNH}^{+}\right.$ & $104(5.4)$ & $138(23.6) / 140(8.4)$ & $149(13.0)$ & $118(65.5)$ & $134(17.1)$ \\
$\left(\mathrm{ArCN}^{+}\right.$ & $103(12.9)$ & $137(21.6) / 139(9.4)$ & $148(2.1)$ & $117(29.0)$ & $133(25.0)$ \\
$\mathrm{Ar}^{+}$ & $77(100)$ & $111(100) / 113(30.9)$ & $122(<1)$ & $91(100)$ & $107(21.1)$ \\
\hline
\end{tabular}

* Values reported are: $m / z$ (relative abundance, $\%$ ).

\subsection{Reagents}

All the reagents have been commercially acquired and have been used without further treatment:

- Thiosemicarbazide. Sigma-Aldrich, St. Louis, MO, USA, 99\%,

- Acetophenone. Sigma-Aldrich, St. Louis, MO, USA, 99\%,

- 4-chloroacetophenone. Sigma-Aldrich, St. Louis, MO, USA, 97\%,

- 4-nitroacetophenone. Sigma-Aldrich, St. Louis, MO, USA, 98\%,

- 4-methylacetophenone. Sigma-Aldrich, St. Louis, MO, USA, $\geq 95 \%$,

- 4-Methoxyacetophenone. Sigma-Aldrich, St. Louis, MO, USA, $\geq 98 \%$.

\subsection{Structural Determinations}

\subsubsection{Gas Chromatography-Mass Spectrometry-Single Quadrupole}

These determinations were performed by injection of dimethyl sulfoxide solutions $\left(0.5-1 \mu \mathrm{L}, 15 \mathrm{mg} \cdot \mathrm{mL}^{-1}\right)$ in an HP 5890 Chromatograph connected to an HP 5972 A mass selective detector (Hewlett-Packard, Palo Alto, CA, USA). An HP5-MS (Hewlett-Packard) capillary column $(30 \mathrm{~m} \times 0.25 \mathrm{~mm} \times 5 \mu \mathrm{m})$ was used with helium (99.999\%) as the carrier gas $\left(0.6 \mathrm{~mL} \cdot \mathrm{min}^{-1}\right.$ in the column, split ratio $1: 30$ ). The temperatures set points were: $250^{\circ} \mathrm{C}$ in the split injector, $300^{\circ} \mathrm{C}$ in the interface, $280^{\circ} \mathrm{C}$ in the ion source and the oven ramp started at $100^{\circ} \mathrm{C}(5$ min) and ended at $350^{\circ} \mathrm{C}$ with a heat rate of $10^{\circ} \mathrm{C} \cdot \mathrm{min}^{-1}$. The electron energy was $70 \mathrm{eV}$ and the pressure in the mass spectrometer was about $10^{-5}$ torr, thus precluding ion-molecule reactions. These determinations were carried out to examine the mass spectrometric behavior of these compounds which could exhibit tautomeric equilibria and are thermolabile.

\subsubsection{Gas Chromatography-Mass Spectrometry-Ion Trap}

These determinations were carried out by injection of solutions of compound III 
in DMSO $(1 \mu \mathrm{L})$ in a Thermo Quest Trace 2000 Chromatograph coupled to a Finnigan Polaris ion trap detector (unit mass resolution) (Thermo Electron, San Jose, CA, USA) under the same temperature, pressure and electron energy conditions mentioned for the quadrupole system. The ion trap was utilized to confirm the proposed fragmentation pathways by collision induced dissociation (CID) using Helium as the damping gas, a CID voltage of $4-8 \mathrm{eV}$ and excitation energy of 0.3 - 0.5 (optimized for each transition). MS/MS full scan ion product spectra were recorded for selected precursor ions.

\subsubsection{Nuclear Magnetic Resonance}

${ }^{1} \mathrm{H}$ NMR spectra in DMSO- $\mathrm{d}_{6}$, were recorded with a Varian Mercury Plus spectrometer (Varian, Agilent Technologies, Palo Alto, CA, USA), $200 \mathrm{MHz}$ (Table 2). Deuterium from the solvent was used as the lock and TMS as the internal standard. Sample concentration was $20 \mathrm{mg} / \mathrm{ml}$. Measurements were performed at $25^{\circ} \mathrm{C}$.

\subsubsection{Computational Procedures}

Geometry optimization of the molecules involved in the processes was accomplished using the Becke's three parameters hybrid density functional [16] with the gradient-corrected correlation functional due to Lee, Yang and Parr [17], a combination that gives rise to the well-known B3LYP functional [18]. In order to confirm that the obtained structures are local minimum on the potential energy surface, the eigenvalues of the hessian matrix of the electronic energy, with respect to the atomic coordinates, were inspected. The double-hybrid RI-PWPB95 functional [19], including the D3 dispersion correction due to Grimme [20] and the Becke-Johnson damping function [21], were used to obtain a better estimation of total electronic energies from single point calculations on previously optimized geometries. The def2-SVP and the def2-QZVPP basis sets [22] were utilized for geometry optimizations and for single-point calculations, respectively. All the calculations were carried out with the ORCA package [23].

Table 2. ${ }^{1} \mathrm{H}$ NMR of selected thiosemicarbazones of acetophenones in DMSO- $\mathrm{d}_{6}$.

\begin{tabular}{llllll}
\hline \multicolumn{5}{c}{${ }^{1} \mathrm{H}$ NMR Data, $\boldsymbol{\delta}, \mathrm{ppm}$, Multiplicity } \\
& $\mathrm{NH}_{2}$ & $\mathrm{NH}$ & $\mathrm{CH}_{3}$ & Aromatic protons & Aromatic Substituent \\
\hline I & $6.55, \mathrm{~s}^{\mathrm{a}}$ & $8.85, \mathrm{~s}$ & $2.30, \mathrm{~s}$ & $7.40-7.55, \mathrm{~m}$ & - \\
& & & & & \\
II & $8.00, \mathrm{~s}$ & $10.25, \mathrm{~s}$ & $2.30, \mathrm{~s}$ & $7.40, \mathrm{~d}-7.95, \mathrm{~d}$ & - \\
& $8.30, \mathrm{~s}$ & & & & - \\
III & $8.05, \mathrm{~s}$ & $10.45, \mathrm{~s}$ & $2.40, \mathrm{~s}$ & $8.15, \mathrm{~d}-8.30, \mathrm{~d}$ & - \\
IV & $8.45, \mathrm{~s}$ & & & & $2.15, \mathrm{~s}$ \\
V & $7.00, \mathrm{~s}^{\mathrm{a}}$ & $10.10, \mathrm{~s}$ & $2.30, \mathrm{~s}$ & $7.25-7.80, \mathrm{~m}$ & $3.80, \mathrm{~s}$ \\
\hline
\end{tabular}

a This signal integrates ${ }^{1} \mathrm{H}$, the other is mixed within the aromatic protons' signals. 


\section{Results and Discussion}

\subsection{Gas Chromatography-Mass Spectrometry}

Figure 1 shows the total ion chromatogram (TIC) after injection of the thiosemicarbazone of 4-methylacetophenone (IV), which has been object of study in a previous work [9].

The mass spectrum of the peak at 5.2 minutes due to the thiosemicarbazone of acetophenone (I) is included in Table 1. As it can be seen, there are two chromatographic peaks. Peak purity allowed discarding co-elution in any of the observed peaks. The second peak at 10.2 minutes is due to a compound of higher molecular weight that is formed in the injection port [9].

For the spectrum of the thiosemicarbazone of acetophenone, Scheme 2 shows the corresponding fragmentation routes. Ammonia loss has a very low energy requirement thus precluding the observation of the molecular ion in the spectrum. Schemes notations for fragmentation mechanisms are: $\boldsymbol{\alpha}$ (alpha rupture), i (inductive cleavage), $\mathbf{r H}$ (Hydrogen rearrangement), $\mathrm{rd}$ (displacement reaction) and Hom. (homolytic cleavage). This last fragmentation pathway is somehow unusual and not favored for even-electron ions. This work gives support to these mechanisms not only from the mass spectrometric data but also from theoretical calculations discussed later.
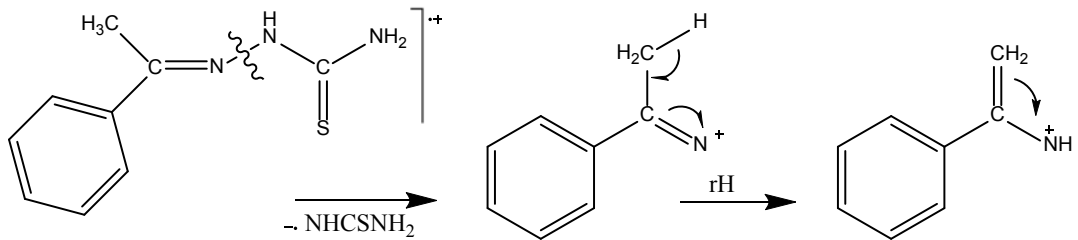

$\mathrm{m} / \mathrm{z} 193$

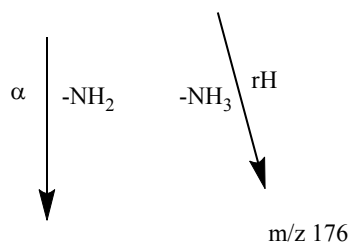

$\mathrm{m} / \mathrm{z} 177$

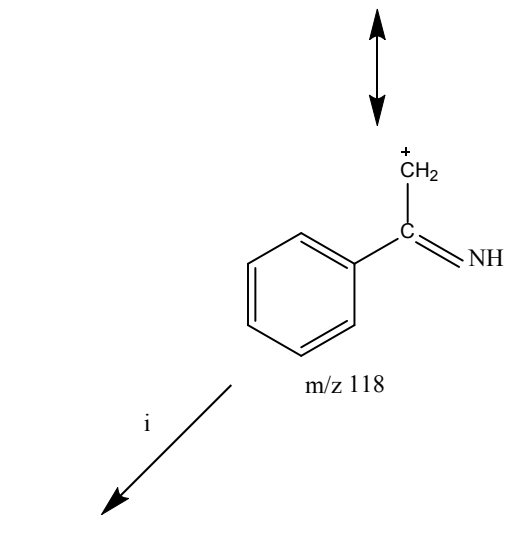

$\mathrm{m} / \mathrm{z} 77$
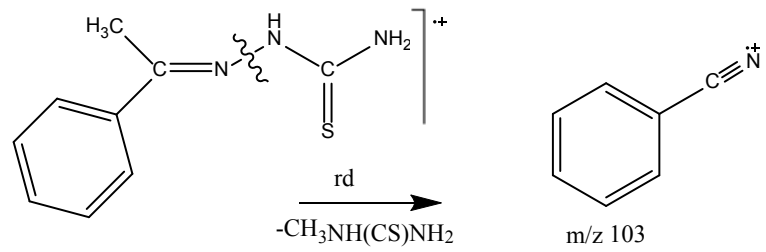


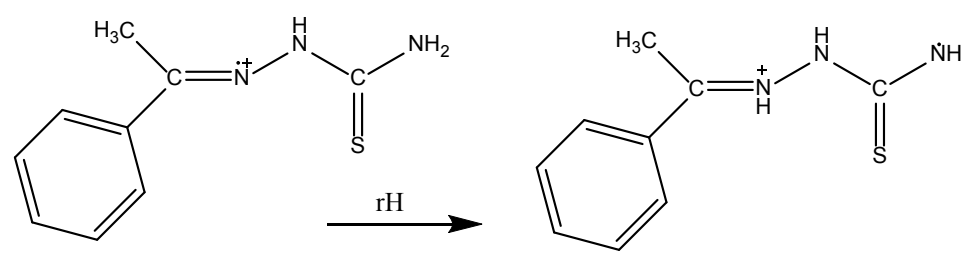

$\mathrm{m} / \mathrm{z} 193$
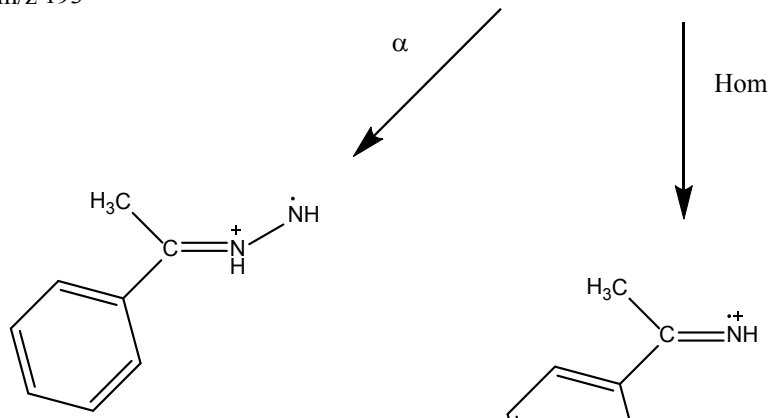

$\mathrm{m} / \mathrm{z} 134$

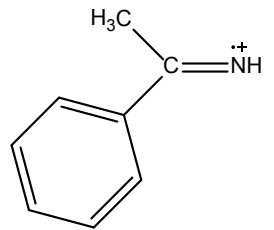

$\mathrm{m} / \mathrm{z} 119$
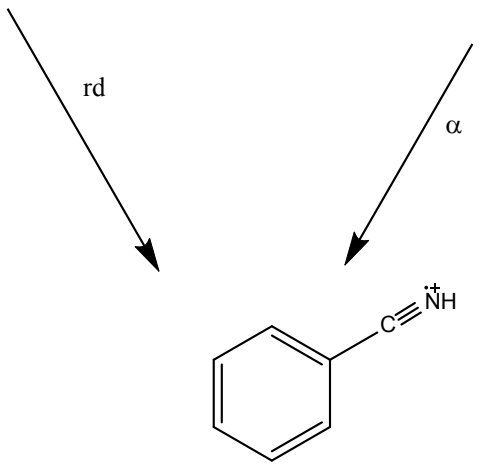

$\mathrm{m} / \mathrm{z} 104$

Scheme 2. Fragmentation routes of the thiosemicarbazone of acetophenone.

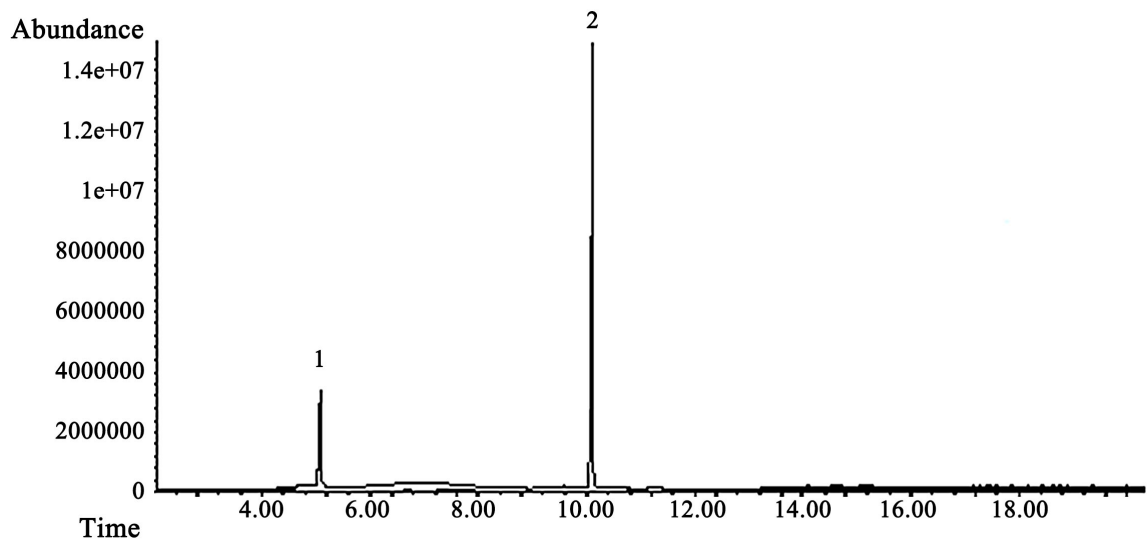

Figure 1. Chromatographic peaks observed after GC-MS analysis of IV at $250^{\circ} \mathrm{C}$ in the injection port.

The inductive cleavage in the most stable open-chain tautomer $\left(T_{1}\right)$ forms the ion at $m / z 118$ that decomposes inductively to form the ion at $\mathrm{m} / \mathrm{z} 77$. It is inter- 
esting to observe the substitution effect exerted by the electron donor oxymethyl-group which maximized the abundance of the $\mathrm{m} / \mathrm{z} 148$ (analogue to $\mathrm{m} / \mathrm{z} 118$ of I) and the opposite effect exerted by the nitro-group (electron-withdrawing substituent) on the abundance of the ion at $\mathrm{m} / \mathrm{z} 122$ (analogue to $\mathrm{m} / \mathrm{z} 77$ of I, very low abundant) due to its increased instability. Substituent effects also apply to the relative abundance of the ion at $\mathrm{m} / \mathrm{z}$ 103: electron donor oxymethyl-group increases the corresponding abundance of the ion at $m / z 133$ and the nitro-group decreases it $(\mathrm{m} / \mathrm{z}$ 148). A rather unusual fragmentation pathway is observed to form the radical ion at $\mathrm{m} / z 119$ from the rearranged molecular ion. The occurrence of the homolytic cleavage is a consequence of the relatively low energy requirement to break the N-N bond. The fragmentation pathways have been confirmed by GC-MS ${ }^{2}$ (Ion trap, see experimental part), with the exception of those coming from the molecular ion which has not been observed.

For all studied thiosemicarbazones the easy loss of ammonia is also the reason for the molecular ion absence in their spectra.

The ion at $\mathrm{m} / z \quad 168$ in the spectrum of the thiosemicarbazone of 4-chloroacetophenone (II) is due to an easy loss of $\mathrm{S}=\mathrm{C}=\mathrm{NH}$ from the molecular ion.

The mass spectrum of the thiosemicarbazone of 4-nitroacetophenone (III), has the base peak at $m / z 117$ (not included in Table 1) which is the loss of a nitro-group, typical of nitroaromatics, from the ion at $\mathrm{m} / z 163$ rendering the radical ion $\mathrm{C}_{6} \mathrm{H}_{4} \mathrm{CH}_{3} \mathrm{CN}^{+}$. Its structure would be similar to that one for the $\mathrm{m} / \mathrm{Z} 118$ in Scheme $2\left(\mathrm{C}_{6} \mathrm{H}_{5} \mathrm{CH}_{3} \mathrm{CN}^{+}\right.$, even-electron ion). The loss of the electron-withdrawing $\mathrm{NO}_{2}$ group is not favored in the molecular ion, but the opposite effect would take place in the ion at $\mathrm{m} / \mathrm{z} 163$. Nitroaromatics are characterized by $\mathrm{NO}_{2}$ and NO losses which are not observed from the molecular ion, but they can be observed from the fragment ions having positive charge density close to the ring (Scheme 3).<smiles>[CH2]C(=N)c1ccc([N+](=O)[O-])cc1</smiles>

$\mathrm{m} / \mathrm{z} 163$
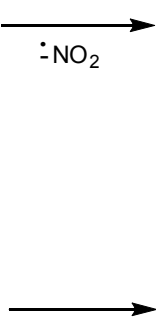

$-\mathrm{NO}$<smiles>[C+]C(=N)c1ccccc1</smiles>

$\mathbf{m} / \mathbf{z} 117$

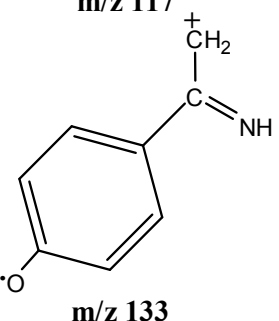

Scheme 3. $\mathrm{NO}_{2}$ and $\mathrm{NO}$ losses in nitroaromatic ions. 
In fact, the ions having positive charge density close to the ring $\left(\mathrm{CH}_{2}^{+}\right.$, wich would exert an electron-withdrawing inductive effect opposite to that of the nitro-group) seem to exhibit both losses (Table 3). The mass spectrum of the thiosemicarbazone of 4-nitroacetophenone (III) is shown in Figure 2.

The fragmentation pathways have been confirmed by GC-MS² (Ion trap, see experimental part).

This mass spectral behavior has been observed for every compound under study. The fragmentations shown in Scheme 1 are present in all spectra. Some of the corresponding ions relative abundances are easily interpreted by substituent effects as it was mentioned for some fragmentations. It should be remarked that there is no indication of a tioenol-tautomer as observed for other families of compounds, [24] usually by detection of the ions $[\mathrm{M}-\mathrm{SH}]^{+}$or $\left[\mathrm{M}-\mathrm{SH}_{2}\right]^{+}$in their mass spectra. Clearly, this observation does not imply its absence.

For the thiosemicarbazone of 4-chloroacetophenone (II), the observation of the ion at $m / z 168 / 170$ in the highest mass region of the mass spectrum would be due to the relatively easier loss of $\mathrm{S}=\mathrm{C}=\mathrm{NH}$ from the corresponding molecular ion. The same explanation applies to the $\mathrm{m} / \mathrm{z} 179$ of the thiosemicarbazone of 4-nitroacetophenone (III). The lowest relative intensity observed for III of $\mathrm{Ar}^{+}$is clearly due to the $\mathrm{NO}_{2}$ electronic effect. The ion at $m / z 148$ in the mass spectrum of the thiosemicarbazone of 4-methoxyacetophenone $(\mathrm{V})$, base peak, is an indication of the stabilizing effect of the methoxy-group.

Evidence for the occurrence of a thiol-tautomer in thiosemicarbazones has been obtained after the methylation of the thiosemicarbazone of acetophenone (I). The mass spectrum of the corresponding product exhibit a prominent $\left(\mathrm{M}-\mathrm{SCH}_{3}\right)^{+}, \mathrm{m} / \mathrm{z} 160,10.1 \%$. Figure 3 shows this experimental result for the methylation product of the thiosemicarbazone of 4-nitroacetophenone (III) which also exhibits the same fragmentation, $\mathrm{m} / \mathrm{z} 205,31.5 \%$. Theoretical calculations (see below) support the highest stability of the thioketo-form $\left(T_{1}\right)$ followed by the thioenol-form $\left(\mathrm{T}_{2}\right)$. It is assumed that the methylation reaction takes place with the little abundant thiol-tautomer.

\section{2. ${ }^{1} \mathrm{H}$ NMR}

The ${ }^{1} \mathrm{H}$ NMR spectrum for the thiosemicarbazone of 4-nitroacetophenone (III)

Table 3. Products ions from loss of $\mathrm{NO}_{2}$ and $\mathrm{NO}$ in the mass spectrum of the thiosemicarbazone of 4-nitroacetophenone (III).

\begin{tabular}{ccc}
\hline $\begin{array}{c}\text { Precursor Ion } \\
\boldsymbol{m} / \boldsymbol{z} \text { (R.A. \%) }\end{array}$ & $\begin{array}{c}\text { Loss of } \mathrm{NO}_{2} \\
\boldsymbol{m} / \boldsymbol{z} \text { (R.A. \%) }\end{array}$ & $\begin{array}{c}\text { Loss of NO } \\
\boldsymbol{m} / \boldsymbol{z}(\text { R.A. \%) }\end{array}$ \\
\hline $164(18.0)$ & $118(17.6)$ & $134(<1)$ \\
$163(50.3)$ & $117(100)$ & $133(6.3)$ \\
$149(13.0)$ & $103(22.5)$ & $119(6.0)$ \\
$148(2.1)$ & $102(22.4)$ & $118(17.6)$ \\
\hline
\end{tabular}




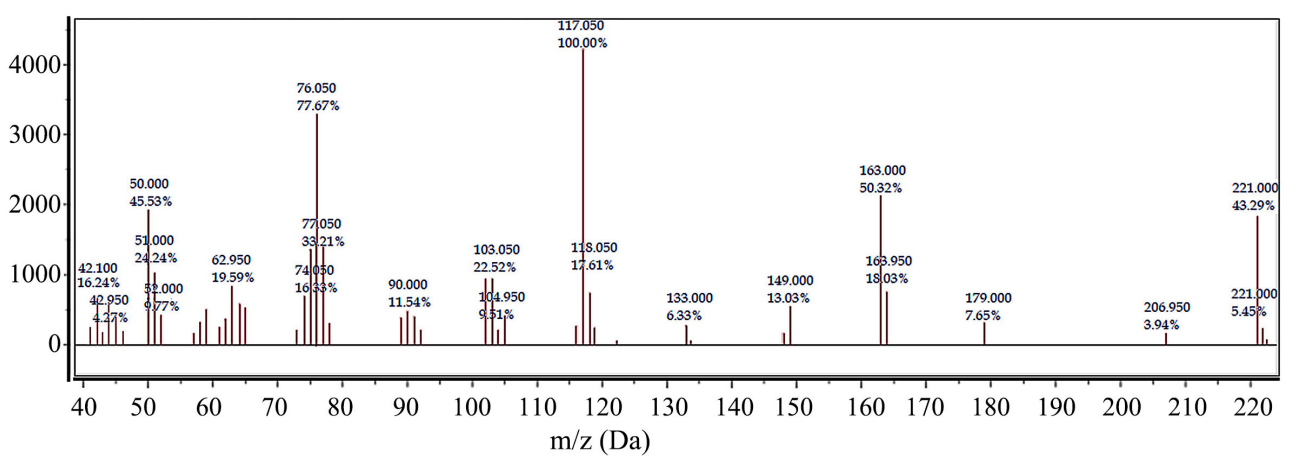

Figure 2. Mass spectrum of the thiosemicarbazone of 4-nitroacetophenone (III).

in dimethylsulfoxide- $\mathrm{d}_{6}$ is described in Table 2 . The registered spectrum would correspond to the open-chain thioketo-tautomer. The $\mathrm{NH}_{2}$ group in all cases is responsible for two signals in the ${ }^{1} \mathrm{H}$ NMR spectra. The reason for this behavior could be assigned to a "slow" C-N rotation in the thioamide-moiety along with the interaction of one of the protons with the $\mathrm{sp} 2$ nitrogen atom establishing a five-member ring hydrogen bonding which would shift the corresponding signal to lower fields.<smiles></smiles>

An interesting result is observed in the spectrum of III in deuterated trifluoroacetic acid (Figure 4), where not only it is possible to detect the occurrence of the open thioketo-form but also a tautomeric ring structure which turns to be predominant. The chemical shifts of the aromatic protons in the $p$-phenyl moiety are consistent with the occurrence of two forms in equilibrium: the open-form $T_{1}$ and a ring structure (Scheme 4 ). The signals due to the aromatic protons for the $p$-substituted compound revealed two pairs of double-doublets, one of them with smaller chemical shift difference between the $\mathrm{H}_{\mathrm{A}}$ and $\mathrm{H}_{B}$. This might be explained by the protonation on the nearest nitrogen in both tautomers: for the open-chain form, the chemical shift for $\mathrm{H}_{\mathrm{A}}$ is closer to that one of $\mathrm{H}_{\mathrm{B}}$ compared to the corresponding chemical shifts for the ring structure. Stronger substituent effects take place in the open-chain (opposite electronwithdrawing effect) and are not significant in the ring structure where conjugation with the aromatic ring is absent. The signal of the doublet around $8.5 \mathrm{ppm}$ would be the result of signal superposition for both tautomers in equilibrium.

All the protons in $\mathrm{NH}$ are collapsed at low fields due to the presence of a significant amount of TFA not completely deuterated. 


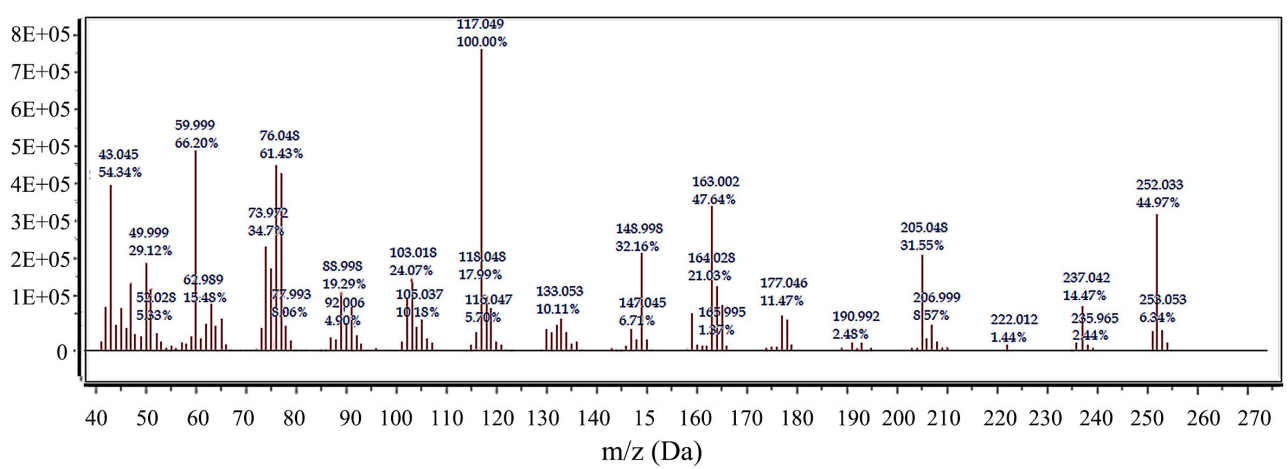

Figure 3. Mass spectrum of the methylation product of the thiosemicarbazone of 4-nitroacetophenone (III).

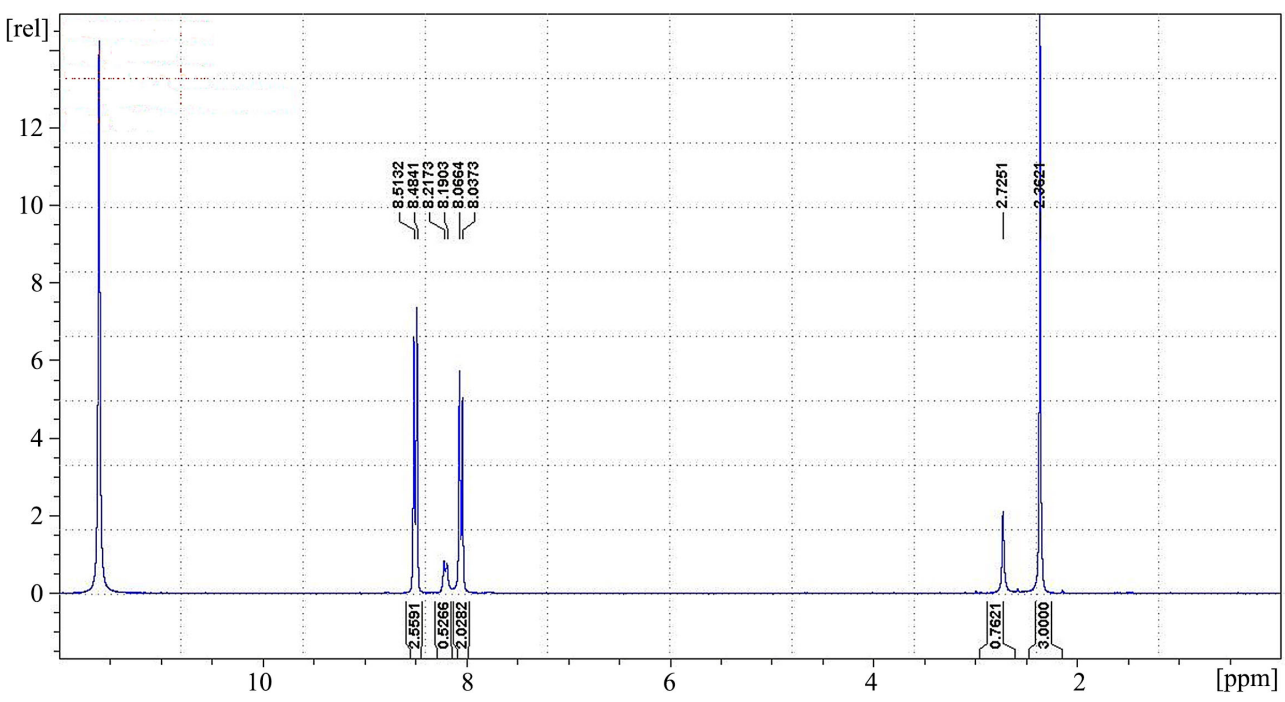

Figure 4. 1H NMR spectrum of the thiosemicarbazone of 4-nitroacetophenone (III) in deuterated TFA.<smiles>C=CC=C</smiles><smiles>CC1(c2ccc([N+](=O)[O-])cc2)NN=C(N)S1</smiles>

Scheme 4. Equilibrium open-chain tautomer $\left(T_{1}\right)$ - ring structure $\left(T_{9}\right)$ in TFA.

The signal assignments in the spectra suggest that the ring structure might correspond to the tautomer-form $\mathrm{T}_{9}$. Additional support has been resourced by theoretical calculations.

\subsection{Theoretical Calculations}

Relative formation energies for the tautomers of thiosemicarbazones in the gas phase are depicted in Table 4. Some DFT calculations in ethanolic solutions have been reported [25]. Fifteen tautomers are possible taking into consideration 
Table 4. Formation enthalpies for the tautomers of thiosemicarbazones $\left(\mathrm{kcal} \cdot \mathrm{mol}^{-1}\right)$.

\begin{tabular}{|c|c|c|c|c|c|c|c|c|c|c|c|c|c|c|c|}
\hline \multirow{2}{*}{ Thio semi carb. } & \multicolumn{8}{|c|}{ Open Chain } & \multicolumn{7}{|c|}{ Ring Structure } \\
\hline & $\mathrm{T}_{1}$ & $\mathrm{~T}_{2}$ & $\mathrm{~T}_{3}$ & $\mathrm{~T}_{4}$ & $\mathrm{~T}_{5}$ & $\mathrm{~T}_{6}$ & $\mathrm{~T}_{7}$ & $\mathrm{~T}_{8}$ & $\mathrm{~T}_{9}$ & $\mathrm{~T}_{10}$ & $\mathrm{~T}_{11}$ & $\mathrm{~T}_{12}$ & $\mathrm{~T}_{13}$ & $\mathrm{~T}_{14}$ & $\mathrm{~T}_{15}$ \\
\hline I & 59.2 & 62.4 & 77.9 & 72.5 & 70.0 & 70.7 & 67.0 & 76.5 & 59.1 & 64.8 & 69.7 & 63.4 & 63.8 & 64.5 & 75.0 \\
\hline II & 50.1 & 52.7 & 68.5 & 68.8 & 60.9 & 61.9 & 57.4 & 67.2 & 49.2 & 55.4 & 60.5 & 53.9 & 54.6 & 55.5 & 64.8 \\
\hline III & 55.6 & 57.5 & 73.7 & 68.8 & 66.3 & 67.1 & 62.0 & 72.4 & 53.9 & 60.4 & 65.9 & 58.8 & 60.0 & 60.8 & 68.9 \\
\hline IV & 49.3 & 52.5 & 58.0 & 63.0 & 60.1 & 60.6 & 57.1 & 66.7 & 49.2 & 54.9 & 59.7 & 53.6 & 53.8 & 54.6 & 65.3 \\
\hline V & 19.0 & 22.0 & 30.2 & 32.4 & 29.8 & 30.3 & 26.8 & 36.4 & 18.7 & 24.6 & 29.3 & 23.0 & 23.4 & 24.1 & 34.9 \\
\hline
\end{tabular}

the open-chain forms and the cyclic ones (Scheme 1). In any case, these two families of tautomers are not likely to interconvert easily since cycloadditions reactions have to take place involving a high entropic requirement. For the thiosemicarbazones, the open-chain keto-form is the most stable in all cases $\left(\mathrm{T}_{1}\right)$. Among the open-chain forms, the next most stable is $T_{2}$ what is consistent with the methylation results and the corresponding mass spectrum (Figure 3 ).

The bond dissociation energy for the homolytic fragmentation of the N-N bond of the ion shown in Scheme 2 was calculated to be $3.42 \mathrm{eV}$ (at $298^{\circ} \mathrm{K}$ ). For comparison purposes, the bond dissociation energy for the homolysis of an even-electron ion in which the nitrogen atom is bound to an sp3 carbon atom, was also calculated. In this case, the bond dissociation energy is considerably higher, namely $4.67 \mathrm{eV}$, rendering also the ion at $\mathrm{m} / z 119$ (Scheme 5). So that, this ion would be mainly formed by the homolytic route. The analogous observation was reported for the homolytic rupture between sp- and sp2-nitrogens atoms (compared to the rupture between sp-nitrogen and sp2-carbon atoms) for related structures [9].

$\mathrm{T}_{1}$ is the most stable open-chain tautomer (thioketo-), followed by $\mathrm{T}_{2}$ (thioenol-). The cyclic structures are considered separately since their formation implies, at least, a cyclo-addition reaction. Among the ring structures, $T_{9}$ would be the most stable (cycloaddition of $\mathrm{T}_{2}$ involving the $\mathrm{SH}$ group) followed by $\mathrm{T}_{12}$ (with a thiol-group), with formation energy very closed to that one of $T_{13}$ (with a thiocarbonyl-group). Both $\mathrm{T}_{9}$ and $\mathrm{T}_{12}$ exhibit a 4-center conjugated system $\left(-\mathrm{NH}-\mathrm{N}=\mathrm{C}-\mathrm{NH}_{2}\right.$ and $-\mathrm{NH}-\mathrm{N}=\mathrm{C}-\mathrm{SH}$ respectively what might account for their relative stabilities). It is interesting that $\mathrm{T}_{12}$ would be the cycloaddition product from $T_{2}$ and $T_{13}$ that one from $T_{1}$, in both cases the cycloaddition would involve the $\mathrm{NH}_{2}$ group (Scheme 6). As experimentally observed, high acidic media is necessary. Very good support for the occurrence of the tautomeric ring structure is provided by NMR studies in highly acidic media (Trifluoracetic acid).

This result is observed for all the thiosemicabazones under study.

Additionally, there is a clear indication of the stabilizing effect of the oxymethyl-group (compound V) on the formation energies (Table 4) followed in less extend by the methyl-group (compound IV), both electron-donating substituents. This effect might be related to the occurrence of the electron-withdrawing moiety on the other side of the molecules. 

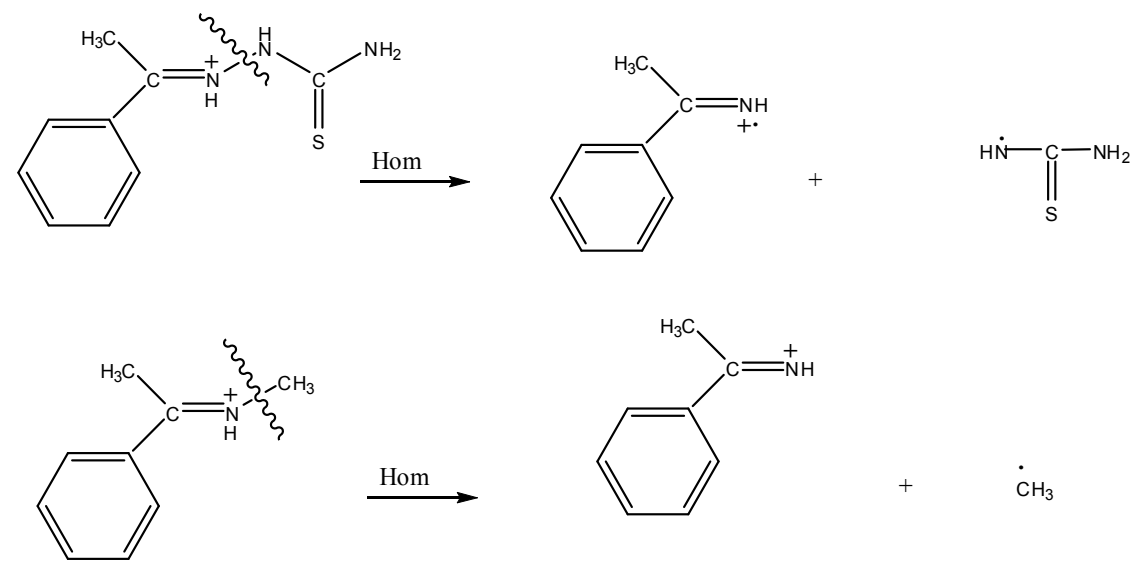

Hom

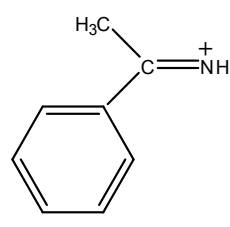

$+\quad \dot{\mathrm{CH}_{3}}$

Scheme 5. Homolytic cleavage calculations.<smiles>C/C(=N/NC(=S)NC1CC1)c1ccccc1</smiles><smiles>C=N/C(S)=N\N=C(\C)c1ccccc1</smiles><smiles></smiles><smiles>C=CC=C</smiles><smiles>CC1(c2ccccc2)NN=C(S)N1</smiles>

Scheme 6. Most stable open-chain thiosemicarbazones tautomers and their cycloaddition products (most stable ring tautomers).

\section{Conclusions}

Mass Spectrometry and Nuclear Magnetic Resonance has been utilized to provide evidence about the most stables tautomeric structures of thiosemicarbazones of substituted acetophenones. Among the 15 tautomeric structures (8 open-chain forms and 7 ring forms) this study allows to propose that:

- considering the open-chain tautomers, there is one thioketo-form that predominates $\left(T_{1}\right)$ followed by the thioenol-tautomer $\left(T_{2}\right)$ as evidenced by the methylation reaction,

- considering the ring tautomers (not easily interconverted with the open-chain tautomers), there is one S-ring structure that seems to predominate $\left(T_{9}\right)$ in highly acidic media.

These structural experimental studies have been additionally supported by theoretical calculations at DFT level.

\section{Acknowledgements}

Financial support is highly acknowledged to Facultad de Ciencias Exactas, UNLP, and UNLP (La Plata National University), Buenos Aires, Argentina. M. 
Schiavoni is member of CIC (Province of Buenos Aires) Argentina. M. Caputo and H. R. Sánchez acknowledge CONICET for a PhD and Post-Doctoral fellowships, respectively.

\section{Declarations}

Availability of data and material: available as required.

\section{Competing Interests}

It should be noticed that none of the authors have any competing interests in relation with this work.

\section{Authors' Contributions}

Gastaca and Caputo have been involved in the experimental setup and results presentation, Menestrina has run spectrometric data, Sanchez has done theoretical calculations, Schiavoni and Furlong are responsible for data interpretation and report.

\section{References}

[1] Tenório, R.P., Góes A.J.S., de Lima, J.G., de Faria, A.R., Alves, A.J. and de Aquino, T.M. (2005) Tiosemicarbazonas: métodos de obtenção, aplicações sintéticas e importância biológica. Química Nova, 28, 1030-1037. https://doi.org/10.1590/S0100-40422005000600018

[2] Du, X.-H., Guo, C., Hansell, E., Doyle, P.S., Caffrey, C.R., Holler, T.P., McKerrow, J.H. and Cohen, F.E. (2002) Synthesis and Structure-Activity Relationship Study of Potent Trypanocidal Thio Semicarbazone Inhibitors of the Trypanosomal Cysteine Protease Cruzain. Journal of Medicinal Chemistry, 45, 2695-2707. https://doi.org/10.1021/jm010459j

[3] Yu. Ershov, A., Koshmina A.N.V., Mokeev, M.V. and Gribanov, A.V. (2003) The Isoxazolidine-1,2,4-Triazolidine-3-Thione Tautomeric System. Chemistry of Heterocyclic Compounds, 39, 1257-1258. https://doi.org/10.1023/B:COHC.0000008277.45834.c5

[4] Zelenin, K.N., Kuznetsova, O.B., Alekseyev, V.V., Terentyev, P.B., Torocheshnikov, V.N. and Ovcharenko, V.V. (1993) Ring-Chain Tautomerism of N-Substituted Thiosemicarbazones. Tetrahedron, 49, 1257-1270. https://doi.org/10.1016/S0040-4020(01)85816-6

[5] Singh, N.K., Singh, S.B., Shrivastav, A. and Singh, S.M. (2001) Spectral, Magnetic and Biological Studies of 1,4-Dibenzoyl-3-Thiosemicarbazide Complexes with Some First Row Transition Metal Ions. Journal of Chemical Sciences, 113, 257-273. https://doi.org/10.1007/BF02708645

[6] Offiong, O.E. and Martelli, S. (1997) Stereochemistry and Antitumor Activity of Platinum Metal Complexes of 2-Acetylpyridine Thiosemicarbazones. Transition Metal Chemistry, 22, 263-269. https://doi.org/10.1023/A:1018416624951

[7] Samanta, B., Chakraborty, J., Shit,S., Batten, S.R., Jensen, P., Masuda, J.D. and Mitra, S. (2007) Synthesis, Characterization and Crystal Structures of a Few Coordination Complexes of Nickel(II), Cobalt(III) and Zinc(II) with N'-[(2-pyridyl)methylene]Salicyloylhydrazone Schiff Base. Inorganica Chimica Acta, 360, 2471-2484. https://doi.org/10.1016/j.ica.2006.12.019 
[8] Arab, S.T. and Emran, K.M. (2008) Structure Effect of Some Thiosemicarbazone Derivatives on the Corrosion Inhibition of $\mathrm{Fe}_{78} \mathrm{~B}_{13} \mathrm{Si}_{9}$ Glassy Alloy in $\mathrm{Na}_{2} \mathrm{SO}_{4}$ Solution. Materials Letters, 62, 1022-1032. https://doi.org/10.1016/j.matlet.2007.05.088

[9] Gastaca, B., Galletti, G., Sánchez, H.R., Pis Diez, R., de las Mercedes Schiavoni, M. and Furlong, J.J.P. (2015) GC/MS Analyses of Thiosemicarbazones Synthesized from Acetophenones: Thermal Decay and Mass Spectra Features. International Journal of Analytical Mass Spectrometry and Chromatography, 3, 1-13. https://doi.org/10.4236/ijamsc.2015.31001

[10] Hohenberg, P. and Kohn, W. (1964) Inhomogeneous Electron Gas. Physical Review, 136, B864-B871. https://doi.org/10.1103/PhysRev.136.B864

[11] Levy, M. (1979) Universal Variational Functionals of Electron Densities, First-Order Density Matrices, and Natural Spin-Orbitals and Solution of the V-Representability Problem. Proceedings of the National Academy of Sciences of the United States of America, 76, 6062-6065. https://doi.org/10.1073/pnas.76.12.6062

[12] Lieb, E.H. (1983) Density Functionals for Coulomb Systems. International journal of quantum chemistry, 24, 243-277. https://doi.org/10.1002/qua.560240302

[13] Kohn,W. and Sham, L.J. (1965) Self-Consistent Equations Including Exchange and Correlation Effects. Physical Review, 140, A1133-A1138. https://doi.org/10.1103/PhysRev.140.A1133

[14] Wheeler, A.S. and Bost, R.W. (1924) 4-Para-Tolylsemicarbazide and Certain Derivatives. Journal of the American Chemical Society, 46, 2813-2816. https://doi.org/10.1021/ja01677a032

[15] Cheronis, N.D.I., Hodnett, E.M.A. and Entrikin, J.B.E. (1968) Semimicro Qualitative Organic Analysis: The Systematic Identification of Organic Compounds. Interscience, Olney, UK.

[16] Becke, A.D. (1993) Density-Functional Thermochemistry. III. The Role of Exact Exchange. The Journal of Chemical Physics, 98, 5648-5652.

https://doi.org/10.1063/1.464913

[17] Lee, C., Yang, W.-Y. and Parr, R.G. (1988) Development of the Colle-Salvetti Correlation-Energy Formula into a Functional of the Electron Density. Physical Review $B, 37,785-789$. https://doi.org/10.1103/PhysRevB.37.785

[18] Stephens, P.J., Devlin, F.J., Chabalowski, C.F. and Frisch, M. J. (1994) Ab Initio Calculation of Vibrational Absorption and Circular Dichroism Spectra Using Density Functional Force Fields. The Journal of Physical Chemistry, 98, 11623-11627. https://doi.org/10.1021/j100096a001

[19] Goerigk, L. and Grimme, S. (2011) Efficient and Accurate Double-Hybrid-Meta-GGA Density Functionals-Evaluation with the Extended GMTKN30 Database for General Main Group Thermochemistry, Kinetics, and Noncovalent Interactions. Journal of Chemical Theory and Computation, 7, 291-309. https://doi.org/10.1021/ct100466k

[20] Grimme, S., Antony, J., Ehrlich, S. and Krieg, H. (2010) A Consistent and Accurate $A b$ Initio Parametrization of Density Functional Dispersion Correction (DFT-D) for the 94 Elements H-Pu. The Journal of Chemical Physics, 132, Article ID: 154104. https://doi.org/10.1063/1.3382344

[21] Grimme, S., Ehrlich, S. and Goerigk, L. (2011) Effect of the Damping Function in Dispersion Corrected Density Functional Theory. Journal of Computational Chemistry, 32, 1456-1465. https://doi.org/10.1002/jcc.21759

[22] Weigend, F. and Ahlrichs, R. (2005) Balanced Basis Sets of Split Valence, Triple Zeta Valence and Quadruple Zeta Valence Quality for H to Rn: Design and Assess- 
ment of Accuracy. Physical Chemistry Chemical Physics, 7, 3297-3305.

https://doi.org/10.1039/b508541a

[23] Neese, F. (2012) The ORCA Program System. Wiley Interdisciplinary Reviews. Computational Molecular Science, 2, 73-78. https://doi.org/10.1002/wcms.81

[24] Furlong, J.J.P., Schiavoni, M.M., Castro, E.A. and Allegretti, P.E. (2008) Mass Spectrometry as a Tool for Studying Tautomerism. Russian Journal of Organic Chemistry, 44, 1725-1736. https://doi.org/10.1134/S1070428008120014

[25] Ghogomu J.N. and Nkungli, N.K. (2016) A DFT Study of Some Structural and Spectral Properties of 4-Methoxyacetophenone Thiosemicarbazone and Its Complexes with Some Transition Metal Chlorides: Potent Antimicrobial Agents. Advances in Chemistry, 2016, Article ID: 9683630. https://doi.org/10.1155/2016/9683630 